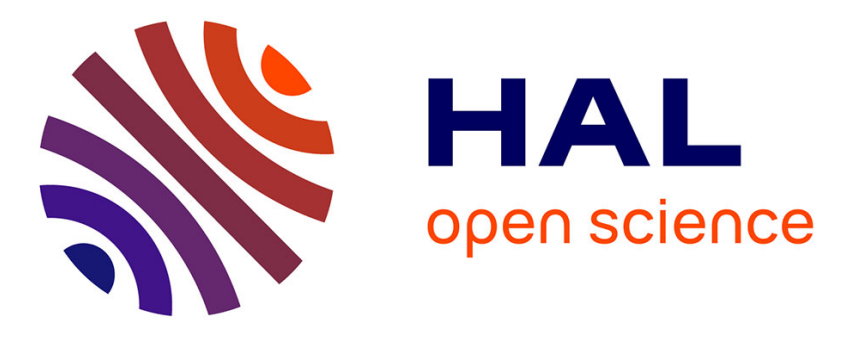

\title{
Observation of a nanoscale phase separation in blue-emitting Ce-doped SiO1.5 thin films
}

Jennifer Weimmerskirch-Aubatin, Mathieu Stoffel, Xavier Devaux, Alexandre

Bouché, Georges Beainy, Etienne Talbot, Philippe Pareige, Yannick

Fagot-Révurat, Michel Vergnat, Hervé Rinnert

\section{To cite this version:}

Jennifer Weimmerskirch-Aubatin, Mathieu Stoffel, Xavier Devaux, Alexandre Bouché, Georges Beainy, et al.. Observation of a nanoscale phase separation in blue-emitting Ce-doped SiO1.5 thin films. Journal of Materials Chemistry C, 2015, 3 (48), pp.12499-12506. 10.1039/c5tc02722e . hal-01271639

\section{HAL Id: hal-01271639 \\ https://hal.science/hal-01271639}

Submitted on 6 Dec 2021

HAL is a multi-disciplinary open access archive for the deposit and dissemination of scientific research documents, whether they are published or not. The documents may come from teaching and research institutions in France or abroad, or from public or private research centers.
L'archive ouverte pluridisciplinaire HAL, est destinée au dépôt et à la diffusion de documents scientifiques de niveau recherche, publiés ou non, émanant des établissements d'enseignement et de recherche français ou étrangers, des laboratoires publics ou privés. 


\title{
Observation of a nanoscale phase separation in blue-emitting $\mathrm{Ce}$-doped $\mathrm{SiO}_{1.5}$ thin films $\dagger$
}

\author{
J. Weimmerskirch-Aubatin, ${ }^{a}$ M. Stoffel, ${ }^{* a} X$. Devaux, ${ }^{a}$ A. Bouché, ${ }^{a}$ G. Beainy, ${ }^{b}$ \\ E. Talbot, ${ }^{b}$ P. Pareige, ${ }^{b}$ Y. Fagot-Révurat, ${ }^{a}$ M. Vergnat ${ }^{a}$ and H. Rinnert ${ }^{a}$
}

\begin{abstract}
Both the optical and structural properties of $\mathrm{Ce}$-doped $\mathrm{SiO}_{1.5}$ thin films were investigated. The Ce-related blue luminescence, which can be seen even at room temperature for as-grown films, exhibits a rather complex evolution with the annealing temperature. In particular, a strong decrease is observed when the films are annealed at $900{ }^{\circ} \mathrm{C}$. Structural characterizations combining scanning transmission electron microscopy and atom probe tomography reveal the formation of $\mathrm{Si}$ - and Ce-rich clusters at this temperature, thus demonstrating that the decreasing Ce-related luminescence is due to concentration induced quenching. For annealing temperatures higher than $900{ }^{\circ} \mathrm{C}$, the Ce-related luminescence increases. The different structural characterizations provide clear experimental evidence of a phase separation occurring at the nanoscale between pure $\mathrm{Si}$ nanocrystals and $\mathrm{Ce}$-rich clusters having a stoichiometry close to the cerium silicates $\mathrm{Ce}_{2} \mathrm{Si}_{2} \mathrm{O}_{7}$ or $\mathrm{Ce}_{4.667}\left(\mathrm{SiO}_{4}\right)_{3} \mathrm{O}$. The latter compounds are optically active thereby explaining the increased $\mathrm{Ce}$-related luminescence observed at the highest annealing temperature.
\end{abstract}

\section{Introduction}

Since bulk Si is an indirect bandgap semiconductor, getting light out of Si-based materials is a challenging issue, not only in the infrared range for telecommunication applications but also in the visible range for displays and white light electroluminescent diodes. At the nanometer scale, the charge carriers are confined in three dimensions, and pure Si nanocrystals embedded in either a $\mathrm{SiO}_{2}{ }^{1}$ or a $\mathrm{Si}_{3} \mathrm{~N}_{4}{ }^{2}$ matrix are shown to emit light in the visible-near infrared range even at room temperature. Moreover, it was shown that a good control of the Si nanocrystal size can be achieved in $\mathrm{SiO} / \mathrm{SiO}_{2}$ multilayers thus allowing us to tune their emission wavelength in the red-near infrared range., ${ }^{3,4}$ The optical properties of Si-based materials containing $\mathrm{Si}$ nanocrystals can be further adjusted by doping the $\operatorname{SiO}_{x}(0<x<2)$ matrix with optically active lanthanide ions. The first studies have concerned the $\mathrm{Er}^{3+}$ doping of $\mathrm{SiO}_{x}$ thin films, which is of potential interest for telecommunications. ${ }^{5}$ More recently, other authors have also studied the doping of $\mathrm{SiO}_{x}$ thin films with $\mathrm{Nd}^{3+}$ ions for photovoltaic applications. ${ }^{6,7}$ In both cases, an efficient energy transfer was found to occur between $\mathrm{Si}$ nanocrystals and $\mathrm{Er}^{3+}$ or $\mathrm{Nd}^{3+}$ ions, thereby enhancing the rare earth based luminescence. If many results were reported for light emission in the red and infrared range, few results were

\footnotetext{
${ }^{a}$ Université de Lorraine, UMR CNRS 7198, Institut Jean Lamour, BP 70239, 54506 Vandœuvre-lès-Nancy, France.E-mail: mathieu.stoffel@univ-lorraine.fr

${ }^{b}$ Groupe de Physique des Matériaux, UMR CNRS 6634, Université et INSA de Rouen, BP 12, Avenue de l'Université, 76801 Saint Etienne de Rouvray, France

$\dagger$ Electronic supplementary information (ESI) available. See DOI: 10.1039/c5tc02722e
}

published for a blue emission in Si-based materials. Among all rare earth elements, Ce is of particular interest since it is characterized by an allowed electric dipolar $5 \mathrm{~d}-4 \mathrm{f}$ transition giving rise to emission in the violet-blue range. This property may be of interest for the development of blue light emitting diodes fully compatible with the Si technology. Morshed et al. ${ }^{8}$ obtained violet-blue luminescence in $\mathrm{CeO}_{2}$ films epitaxially grown on $\mathrm{Si}(111)$ substrates by pulsed laser deposition and subsequently annealed at $1000{ }^{\circ} \mathrm{C}$ in $\mathrm{Ar}$ ambient. The luminescence was tentatively attributed to the formation of a $\mathrm{Ce}_{6} \mathrm{O}_{11}$ compound. Later, Choi et al. ${ }^{9}$ reported violet/blue luminescence in cerium oxide films grown by radio-frequency sputtering directly on $\mathrm{Si}(001)$ substrates. The luminescence was attributed to the formation of cerium silicates. Similar observations were made by Kepinski et $a .^{10}$ in $\mathrm{CeO}_{2}-\mathrm{SiO}_{2}$ films prepared by the sol-gel method and by Li et $a l^{11}$ in Ce-doped silicon oxide thin films grown by electron cyclotron resonance plasma enhanced chemical vapor deposition. By investigating Ce-doped $\mathrm{SiO}_{1.5}$ films prepared by evaporation, we found that $\mathrm{Ce}^{3+}$ ions are mainly directly excited with only a negligible influence of Si nanocrystals. ${ }^{12}$ Finally, strong blue luminescence has also been reported recently in Ce-doped $\mathrm{SiO}_{2}$ thin films prepared by evaporation. ${ }^{13}$

While extensive work has already been performed particularly regarding the optical properties of rare earth doped $\mathrm{SiO}_{x}$ thin films, several critical issues still remain unsolved. In particular, the spatial localization of the rare earth ions with respect to the Si nanocrystals has not yet been addressed. For example, it is not yet clear whether the rare earth ions are located in or at the surface/periphery of the nanocrystals. Moreover, the influence of 
the rare earth ions on Si nanocrystal formation has not yet been studied.

In this study, we investigated the optical and structural properties of Ce-doped $\mathrm{SiO}_{1.5}$ thin films. For all the Ce contents investigated, the Ce-related luminescence follows a similar evolution as a function of the annealing temperature. At $900{ }^{\circ} \mathrm{C}$, a strong decrease of the PL intensity is observed. The structural characterization tools show that both Ce and Si form clusters located at the same position, thus explaining the decreasing luminescence by concentration induced quenching. For annealing temperatures beyond $980{ }^{\circ} \mathrm{C}$, we observe at some locations the beginning of a separation between Ce-rich clusters and $\mathrm{Si}$ nanocrystals. At $1100{ }^{\circ} \mathrm{C}$, we report the first observation of a phase separation occurring at the nanoscale between pure Si nanocrystals and Ce-rich clusters having a stoichiometry close to the cerium silicates $\mathrm{Ce}_{2} \mathrm{Si}_{2} \mathrm{O}_{7}$ or $\mathrm{Ce}_{4.667}\left(\mathrm{SiO}_{4}\right)_{3} \mathrm{O}$. These compounds are known to be luminescent thereby explaining the reappearance of the Ce-related luminescence at this temperature.

\section{Experimental}

The $\mathrm{SiO}_{1.5}$ films were obtained by co-evaporation on $\mathrm{Si}(001)$ or fused silica substrates held at room temperature of SiO powder from a thermal cell and $\mathrm{SiO}_{2}$ from an e-beam gun in an ultrahigh vacuum chamber. The Ce doping was performed by using a Knudsen cell heated at $\sim 1400{ }^{\circ} \mathrm{C}$. The Ce flux was monitored by a quartz microbalance and the Ce content defined by [Ce]/ $([\mathrm{Si}]+[\mathrm{O}]+[\mathrm{Ce}])$ was varied between $0.3 \%$ and $4 \%$. The film thickness was $20 \mathrm{~nm}$ for the samples investigated by transmission electron microscopy and $200 \mathrm{~nm}$ for all other samples considered in this study. The samples were post-grown annealed in either a tubular oven at temperatures between $500{ }^{\circ} \mathrm{C}$ and $900{ }^{\circ} \mathrm{C}$ or in a rapid thermal annealing furnace in a $\mathrm{N}_{2}$ atmosphere at 1100-1200 ${ }^{\circ} \mathrm{C}$. In the case of a tubular oven, the temperature was ramped up with a rate of $10{ }^{\circ} \mathrm{C} \mathrm{min}^{-1}$ up to the desired temperature prior to cooling down, while for the rapid thermal annealing furnace all samples were kept at $1100-1200{ }^{\circ} \mathrm{C}$ for 5 min. The steady state photoluminescence (PL) was excited with a $325 \mathrm{~nm}$ He-Cd laser and subsequently analyzed by a monochromator equipped with a 600 grooves per mm grating and measured by a photomultiplier tube operating in the UV-visible range. A Xe lamp (maximum power $300 \mathrm{~W}$ ) was used as an excitation source for the photoluminescence excitation (PLE) measurements. The response of the detection system was precisely calibrated by a tungsten wire calibration source. The Raman spectra were collected in backscattering geometry using a $532 \mathrm{~nm}$ laser diode as an excitation source. The scattered light was dispersed by a grating with 1800 grooves per $\mathrm{mm}$ and detected by a multichannel charge coupled device (CCD) camera cooled at $200 \mathrm{~K}$. All Raman measurements were performed on samples deposited on fused silica substrates in order to get rid of the contribution of the transverse optical phonon line of the Si substrate. The X-ray photoelectron spectra were measured using the non-monochromatized $\mathrm{AlK}_{\alpha}$ radiation at $1486.6 \mathrm{eV}$. Prior to the measurements, the samples were subjected to a $45 \mathrm{~min}^{+}$ ion bombardment in order to remove potential impurities/ contaminants from the surface. The photoelectrons were collected by a Scienta SES 200 hemispherical analyzer. The overall resolution of the setup was about $0.8 \mathrm{eV}$. The structural properties of the samples were studied by high-resolution transmission electron microscopy (HRTEM) and scanning transmission electron microscopy (STEM) with a JEOL ARM200F. STEM images were simultaneously recorded using high angle annular dark field (HAADF) and bright field (BF) detectors and completed with local energy-dispersive X-ray spectroscopy (EDS). To avoid any phase precipitation due to ion or electron beam damages, the samples were mechanically thinned up to the electron transparency by the tripod method. Both TEM and STEM investigations were performed at $80 \mathrm{kV}$. The 3D mapping of the distribution of atoms in the sample was obtained by laserassisted atom probe tomography (APT) analyses. The tips required for the APT analysis were prepared according to a process used on similar materials as reported elsewhere. ${ }^{14,15}$ The analyses were carried out at $80 \mathrm{~K}$ using a CAMECA LAWATAP instrument with an amplified Ytterbium doped laser emitting at a wavelength of $343 \mathrm{~nm}$ providing a $350 \mathrm{fs}$ pulse duration and a $100 \mathrm{kHz}$ repetition rate with an energy per pulse of around 50 nJ. The infrared absorption spectra are obtained using a Fourier transform infrared absorption spectrometer (FTIR). The films are analyzed at normal incidence by direct transmission. The acquisition of the spectra is performed in absorbance mode. The spectra of the thin films are recorded after subtraction of the reference spectrum measured on a Si substrate. In order to compare the obtained results, a baseline is subtracted from each spectrum to eliminate the interference fringes caused by multiple reflections in the substrate.

\section{Results and discussion}

Fig. 1(a) displays a typical room temperature (RT) steady state PL spectrum of an as-deposited $\mathrm{SiO}_{1.5}$ thin film doped with $3 \%$ Ce (red solid line). We observe strong blue luminescence, which can be seen even with the naked eye (see the inset of Fig. 1(a)).

The PL band is rather broad and extends from $330 \mathrm{~nm}$ to $530 \mathrm{~nm}$ with a maximum centered at $\sim 380 \mathrm{~nm}$. The luminescence may be due to either the defects of the $\mathrm{SiO}_{1.5}$ matrix or the allowed electric dipolar $5 \mathrm{~d}-4 \mathrm{f}$ transition of isolated $\mathrm{Ce}^{3+}$ ions. The former hypothesis can, however, be ruled out since an as-grown and undoped $\mathrm{SiO}_{1.5}$ film does not show any luminescence near $400 \mathrm{~nm}$. Moreover, the PL intensity increases with the Ce content in the films (see also Fig. 1(b)). We can therefore unambiguously attribute the observed luminescence to the allowed electric dipolar 5d-4f transition of $\mathrm{Ce}^{3+}$ ions. In order to determine the excitation mechanism of $\mathrm{Ce}^{3+}$ ions, we further perform PLE measurements. In this case, the detection wavelength is fixed at $450 \mathrm{~nm}$ (this wavelength has been chosen since detection is possible for both as-grown and annealed samples for which the PL signal shifts to higher wavelengths; see also the ESI $\dagger$ ) and the excitation wavelength is varied between $250 \mathrm{~nm}$ and $370 \mathrm{~nm}$. The PLE spectrum, which is shown in Fig. 1(a) as a black solid line, is characterized by a single peak centered at $\sim 300 \mathrm{~nm}$. 

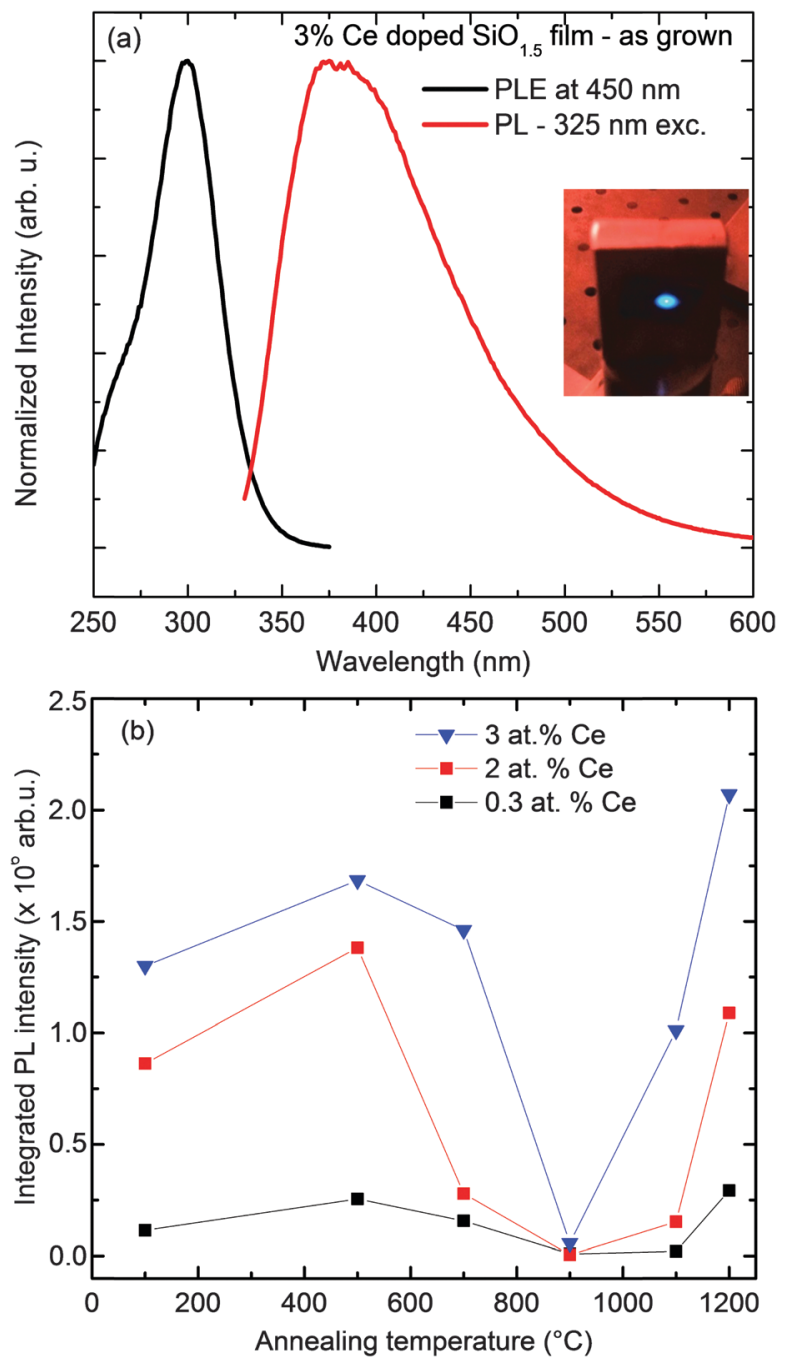

Fig. 1 (a) Steady state PL spectrum of a $3 \% \mathrm{Ce}$-doped $\mathrm{SiO}_{1.5}$ thin film measured at room temperature (red solid line). The corresponding PLE spectrum is shown as a black solid line. The inset shows a photograph of the sample showing the blue luminescence visible with the naked eyes. (b) Integrated Ce-related PL intensity as a function of annealing temperature for three different Ce contents.

This peak is typical for the excitation of the $5 \mathrm{~d}$ levels of $\mathrm{Ce}^{3+}$ ions starting from the fundamental ${ }^{2} \mathrm{~F}_{5 / 2}$ level, thus showing that the $\mathrm{Ce}^{3+}$ ions are mainly directly excited. In the following, we will concentrate our attention on the Ce-related luminescence and its evolution with the annealing temperature. Fig. 1(b) displays the evolution of the integrated Ce-related luminescence as a function of the annealing temperature. It is noteworthy that the evolution follows the same trend independently of the Ce concentration in the films. One can easily distinguish three different regimes. Firstly, from RT up to $500{ }^{\circ} \mathrm{C}$, the integrated luminescence increases. Secondly, from $500{ }^{\circ} \mathrm{C}$ up to $900{ }^{\circ} \mathrm{C}$, the integrated luminescence decreases and eventually reaches a minimum at $900{ }^{\circ} \mathrm{C}$. Thirdly, at higher annealing temperatures up to $1200{ }^{\circ} \mathrm{C}$, the integrated Ce-related luminescence increases. It is important to note that the reappearance of the PL and the existence of a minimum of PL intensity are not due to the annealing treatment method.
Indeed, we carefully checked that a similar qualitative evolution is obtained when the samples are annealed using only the RTA furnace with a minimum of PL intensity occurring at a higher annealing temperature, i.e. $1100{ }^{\circ} \mathrm{C}$. A similar qualitative evolution has already been reported by Li $e t$ al. ${ }^{11}$ in Ce-doped silicon oxide films but the evolution has not been investigated in detail. Interestingly, as the annealing temperature increases, the Ce-related luminescence band shifts to higher wavelength (see $\mathrm{ESI} \dagger$ ). Let us consider the first regime, i.e. from RT up to $500{ }^{\circ} \mathrm{C}$. It is well known that annealing heals out point defects thus leading to a decreased density of non-radiative recombination centers. Consequently, the luminescence increases as observed in Fig. 1(b). We will now consider the second regime corresponding to annealing temperatures between $500{ }^{\circ} \mathrm{C}$ and $900{ }^{\circ} \mathrm{C}$. Li et al. ${ }^{11}$ have interpreted the observed decrease by the precipitation of $\mathrm{Ce}^{3+}$ ions but the existence of Ce rich clusters is unclear and the chemical composition of the clusters remains unknown. Different hypotheses can be put forward to explain the decreased PL intensity. The first one is a modification of the valence of Ce ions evolving from $\mathrm{Ce}^{3+}$ ions to $\mathrm{Ce}^{4+}$ ions. The latter are known to be not optically active which could possibly result in a quenching of the luminescence. The second one is that Ce ions diffuse and form clusters leading to a concentration induced quenching of the luminescence. In order to test the possibility of valence changes, X-ray photoelectron spectroscopy (XPS) measurements of the Ce $3 \mathrm{~d}$ core level were carried out. The different valence states are characterized by well-defined peaks appearing at different binding energies, thus allowing discrimination between $\mathrm{Ce}^{3+}$ and $\mathrm{Ce}^{4+} \cdot{ }^{16,17}$

Fig. 2 shows the Ce $3 \mathrm{~d}$ core levels measured on a $3 \%$ Ce-doped $\mathrm{SiO}_{1.5}$ thin film annealed at $500{ }^{\circ} \mathrm{C}$ (Fig. 2(a)) and at $900{ }^{\circ} \mathrm{C}$ (Fig. 2(b)). The obtained spectra look qualitatively similar to those previously measured on thin $\mathrm{CeO}_{2}$ films deposited on either $\mathrm{Si}(111)$ substrates ${ }^{17}$ or thin Pt foils. ${ }^{16}$ After subtraction of a Shirley background, ${ }^{18,19}$ both spectra were fitted with Gaussian-Lorentzian functions to de-convolve multiple peaks that are closely spaced in binding energy. The spin-orbit splitting between the Ce $3 \mathrm{~d}_{3 / 2}$ and the Ce $3 \mathrm{~d}_{5 / 2}$ peaks was fixed at $18.3 \mathrm{eV}$ as in previous studies. ${ }^{16,17}$ The fitting was performed by using the chemical shifts from the literature ${ }^{16,17}$ and by varying only the height and the full width at half maximum (FWHM) of the peaks. The ratio between the $\mathrm{Ce}^{3+}$ and $\mathrm{Ce}^{4+}$ related peak intensities was then used to determine the amount of Ce ions in the (III)/(IV) oxidation state. In both cases, the contribution of $\mathrm{Ce}^{3+}$ ions is dominant and only a moderate increase of the $\mathrm{Ce}^{4+}$ content is observed when the annealing temperature increased from $500{ }^{\circ} \mathrm{C}$ to $900{ }^{\circ} \mathrm{C}$. We can thus rule out a valence state change as the main origin of the decreased PL intensity observed at $900{ }^{\circ} \mathrm{C}$. To test whether Ce clusters may form, STEM measurements were performed.

Fig. 3 (a) shows a HAADF image of a $3 \%$ Ce-doped $\mathrm{SiO}_{1.5}$ thin film annealed at $900{ }^{\circ} \mathrm{C}$ and the corresponding bright field image is shown Fig. 3(b). One can clearly identify a high density of clusters which exhibit a high contrast (bright on HAADF and dark on $\mathrm{BF}$ ). This observation suggests that they are composed of a heavy element which in our case is Ce. Spatially resolved EDS investigations (Fig. 3(c) and (d)) show that the clusters contain Ce while the surrounding matrix is Ce-free. Moreover, the analysis 

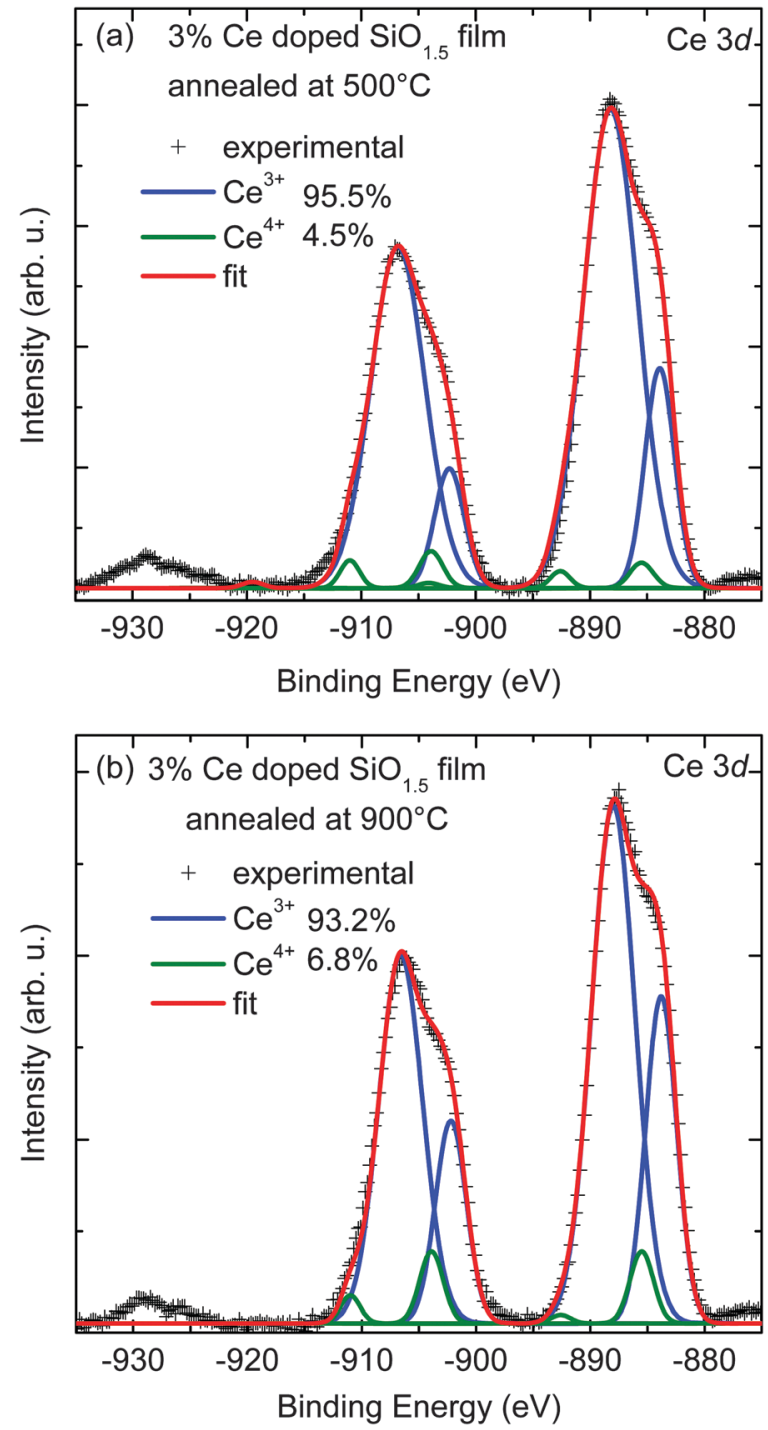

Fig. 2 X-ray photoelectron spectra of the Ce $3 \mathrm{~d}$ core level measured on a $3 \% \mathrm{Ce}$-doped $\mathrm{SiO}_{1.5}$ thin film after annealing at $500{ }^{\circ} \mathrm{C}$ (a) and $900{ }^{\circ} \mathrm{C}$ (b). The result of the fit (solid lines) is superimposed on the experimental data (crosses).

of the HRSTEM images shows that these clusters are amorphous. The demonstration of the formation of Ce-rich clusters allows us to conclude that the decreased PL intensity observed at $900{ }^{\circ} \mathrm{C}$ is the result of concentration induced quenching. If we assume that all Ce ions are randomly distributed in the as-grown films, the observation of Ce clusters in the $900{ }^{\circ} \mathrm{C}$ annealed sample indicates that a significant Ce diffusion must have taken place during annealing. We cannot exclude the possibility that other atomic species of lower mass like Si may also diffuse during high temperature annealing. In order to test the possibility of Si diffusion, we have performed atom probe tomography on the $3 \%$ Ce-doped $\mathrm{SiO}_{1.5}$ thin film annealed at $900{ }^{\circ} \mathrm{C}$.

Fig. 4(a) shows a typical slice view $\left(48.8 \times 48.8 \times 5 \mathrm{~nm}^{3}\right)$ taken from the $3 \mathrm{D}$ reconstructed volume representing $\mathrm{Si}$ atoms for the sample annealed at $900{ }^{\circ} \mathrm{C}$. Oxygen atoms are not represented for clarity reasons. The cartography clearly reveals an inhomogeneous Si distribution with the presence of Si-rich clusters. In contrast, the as-grown sample exhibits a rather uniform Si distribution (not shown here). The presence of Si-rich clusters in the sample annealed at $900{ }^{\circ} \mathrm{C}$ thus indicates that the demixtion of the $\mathrm{SiO}_{1.5}$ film has already started. The excess $\mathrm{Si}$ atoms - by comparison with $\mathrm{SiO}_{2}$ - will diffuse and eventually agglomerate to form the observed clusters as known for undoped $\mathrm{SiO}_{x}$ films. ${ }^{4,20}$ Fig. 4 (b) shows the Ce atoms in the same slice view $\left(48.8 \times 48.8 \times 5 \mathrm{~nm}^{3}\right)$. The cartography gives evidence of the presence of Ce-rich clusters, thus confirming the previous STEM observations. Interestingly, showing both Si- and Ce-related maps (Fig. 4(c)), we found that Ce-rich and Si-rich clusters are located on the same position. Thus, it seems that $\mathrm{Ce}$ atoms do not prevent the demixtion of the $\mathrm{SiO}_{1.5}$ film but instead leads to the formation of Si-clusters containing Ce. Although we have not investigated in detail the diffusion mechanism of both $\mathrm{Si}$ and Ce atoms, we can nevertheless suggest that both atomic species will probably migrate to the pores/vacancies contained in the amorphous $\mathrm{SiO}_{1.5}$ thin films. At the present stage of our investigation, it is not yet clear whether the Si-rich clusters are crystallized or not. To answer this question, Raman measurements have been carried out.

Fig. 5 displays the Raman spectra of a $3 \%$ Ce-doped $\mathrm{SiO}_{1.5}$ film recorded at different annealing temperatures ranging from $900{ }^{\circ} \mathrm{C}$ to $1150{ }^{\circ} \mathrm{C}$. When the film is annealed at $900{ }^{\circ} \mathrm{C}$, the Raman spectrum looks very similar to that of a fused silica substrate indicating that the crystallization of the Si atoms in excess has not yet started. Indeed, the Raman response of amorphous silicon is characterized by a broad and weak peak located at around $480 \mathrm{~cm}^{-1}$. The absence of the Raman signature of the film is interpreted by the presence of silicon in its amorphous state. In contrast, as the film is annealed at $1025{ }^{\circ} \mathrm{C}$, a small peak emerges at $\sim 520 \mathrm{~cm}^{-1}$, i.e. very close to the position of the transverse optical phonon in bulk crystalline Si $\left(520.5 \mathrm{~cm}^{-1}\right)$. We thus conclude that pure Si nanocrystals start to form at temperatures higher than $980{ }^{\circ} \mathrm{C}$. A similar evolution is observed for a $0.7 \%$ Ce-doped $\mathrm{SiO}_{1.5}$ film (not shown here). Moreover, the intensity of the peak observed at $520 \mathrm{~cm}^{-1}$ increases as the annealing temperature increases (see inset of Fig. 5), thus suggesting the formation of a larger number of pure Si nanocrystals. This result is quite surprising since we have shown in Fig. 4(c) that Ce ions have the same locations as $\mathrm{Si}$ atoms. One could thus expect the formation of a $\mathrm{Ce}-\mathrm{Si}-\mathrm{O}$ compound rather than the formation of pure Si nanocrystals. To understand further the evolution of the system, in particular the distribution of the Ce ions in the sample annealed at $980{ }^{\circ} \mathrm{C}$, atom probe tomography experiments were further performed on the $3 \% \mathrm{Ce}$-doped $\mathrm{SiO}_{1.5}$ thin film annealed at $980{ }^{\circ} \mathrm{C}$.

Fig. 6(a) shows a typical slice view $\left(33 \times 33 \times 5 \mathrm{~nm}^{3}\right)$ taken from the reconstructed volume representing Si atoms. Similar to the sample annealed at $900{ }^{\circ} \mathrm{C}$, the distribution of $\mathrm{Si}$ atoms is still inhomogeneous. The same is valid for Ce ions (Fig. 6(b)) as observed previously (Fig. 4(b)). If one shows both Si- and Ce-related atomic maps (Fig. 6(c)), we can recognize that, at some locations, the Ce-rich regions start to be separated from 

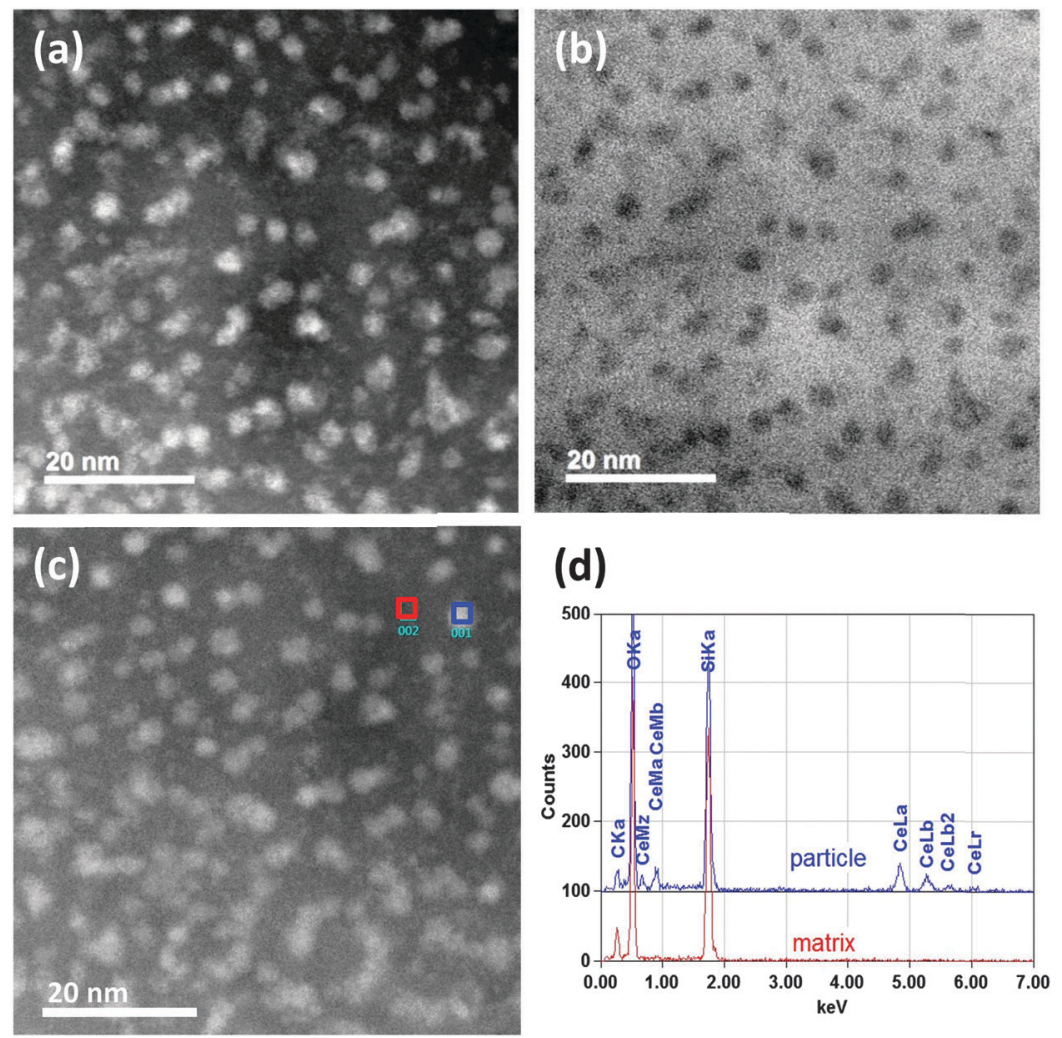

Fig. $3 \mathrm{HAADF}$ image of a $3 \% \mathrm{Ce}$-doped $\mathrm{SiO}_{1.5}$ thin film annealed at $900{ }^{\circ} \mathrm{C}$ showing the presence of $\mathrm{Ce}$-rich clusters (a) and the corresponding bright field image (b). HAADF image (c) showing the areas (red square for the matrix and blue square for a particle) used for the EDS analysis (d)

(a) $\quad \mathrm{Si}$

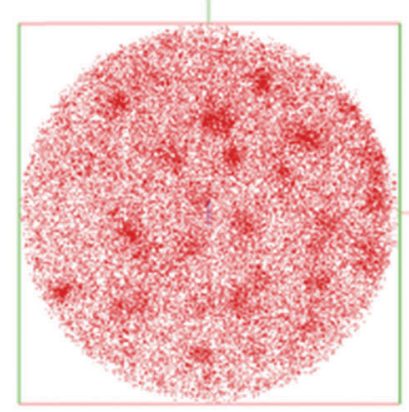

$48.8 \times 48.8 \times 5 \mathrm{~nm}^{3}$ (b) $\quad \mathrm{Ce}$

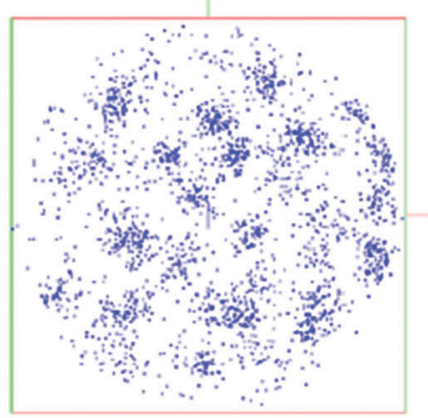

(c) $\quad \mathrm{Si}+\mathrm{Ce}$

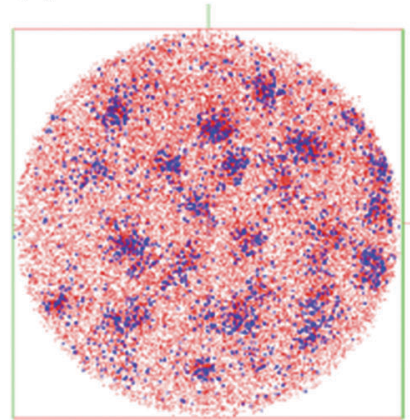

Fig. 4 Atom probe tomography analysis of the $3 \% \mathrm{Ce}$-doped $\mathrm{SiO}_{1.5}$ thin film annealed at $900{ }^{\circ} \mathrm{C}$. (a) Plane view of a $5 \mathrm{~nm}$ thick slice taken from the reconstructed volume. The Si atoms are shown as red dots, providing evidence of the presence of Si-rich clusters, (b) analogous plane view showing Ce atoms as blue dots, evidencing the presence of Ce-rich clusters, (c) superposition of the maps shown in (a) and (b) demonstrating that both Si- and Ce-rich clusters have the same locations. All the views have the size of $48.8 \times 48.8 \times 5 \mathrm{~nm}^{3}$.

the Si nanocrystals as shown by the dashed circles in Fig. 6(c). It would now be interesting to understand how the system evolves at even higher annealing temperatures, for instance at $1100{ }^{\circ} \mathrm{C}$ where the Ce-related luminescence is found to increase (Fig. 1(b)). We thus perform a similar analysis on the $3 \%$ Ce-doped $\mathrm{SiO}_{1.5}$ thin film annealed at $1100{ }^{\circ} \mathrm{C}$.

Fig. 7(a) shows a typical slice view $\left(33 \times 33 \times 5 \mathrm{~nm}^{3}\right)$ taken from the reconstructed volume and representing both $\mathrm{Si}$ atoms (red dots) and Ce atoms (blue dots). While at $980{ }^{\circ} \mathrm{C}$ we observe the beginning of a separation between pure Si nanocrystals and Ce-rich clusters, at $1100{ }^{\circ} \mathrm{C}$, the phase separation now seems to be almost complete. Indeed, the center of mass of the $\mathrm{Si}$ nanocrystals does no longer coincide with the center of mass of the Ce-rich clusters. This is the first experimental evidence of a phase separation occurring at a length scale below $10 \mathrm{~nm}$ in rare earth doped silicon oxide thin films. We then further used atom probe tomography to obtain a better insight into the composition of the Ce-rich clusters. The compositional analysis 


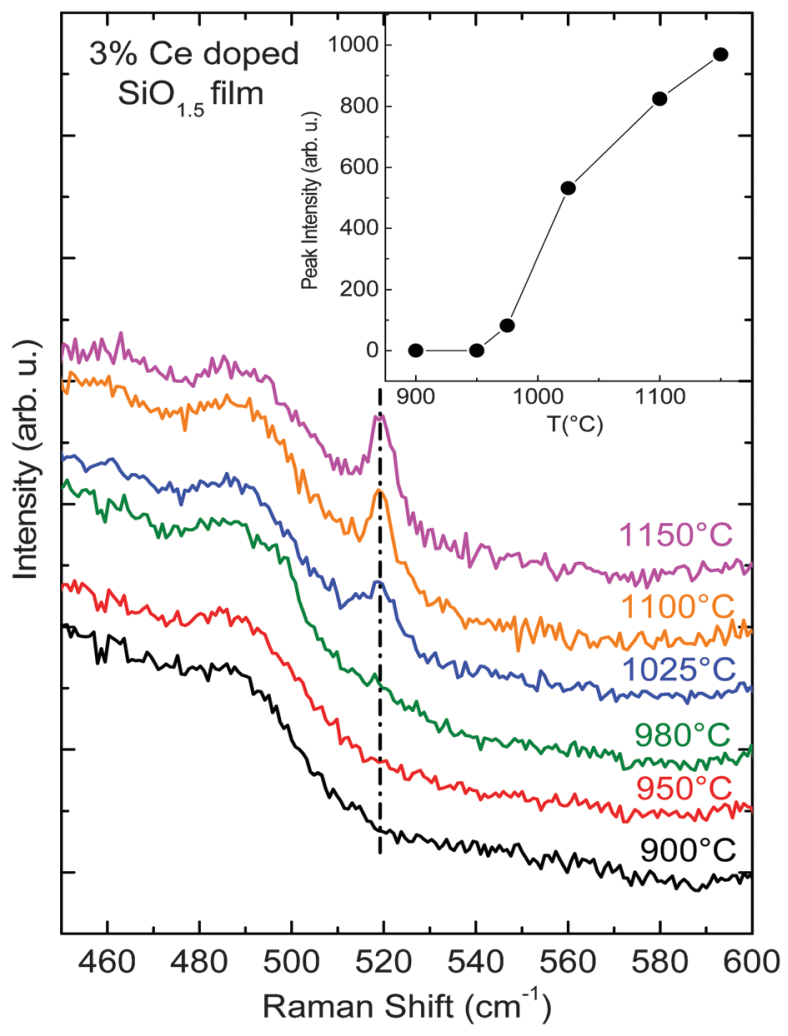

Fig. 5 Raman spectra measured on a $3 \% \mathrm{Ce}$-doped $\mathrm{SiO}_{1.5}$ thin film after annealing at various temperatures between $900^{\circ} \mathrm{C}$ and $1150^{\circ} \mathrm{C}$. All spectra are vertically offset for clarity. The vertical dashed-dotted line indicates the position of the crystalline $\mathrm{Si}-\mathrm{TO}$ peak at $520 \mathrm{~cm}^{-1}$. The inset shows the evolution of the integrated Raman peak intensity at $520 \mathrm{~cm}^{-1}$ as a function of annealing temperature.

reveals that these clusters are indeed composed of Ce but also of $\mathrm{Si}$ and $\mathrm{O}$ with relative amounts $16.3 \%, 18.2 \%$ and $65.5 \%$, respectively. The composition of these clusters appears to be compatible with the formation of cerium silicates of stoichiometry $\mathrm{Ce}_{2} \mathrm{Si}_{2} \mathrm{O}_{7}$ and $\mathrm{Ce}_{4.667}\left(\mathrm{SiO}_{4}\right)_{3} \mathrm{O}$. The latter compounds are known to be luminescent in the violet/blue range. ${ }^{9,11}$ This eventually explains the reappearance of the Ce-related luminescence for samples annealed at $1100{ }^{\circ} \mathrm{C}$ (third regime in Fig. 1(b)). Finally, in order to further strengthen our observations, we investigate the structural properties of the $3 \%$ Ce-doped $\mathrm{SiO}_{1.5}$ film annealed at $1100{ }^{\circ} \mathrm{C}$ by transmission electron microscopy (TEM). Fig. 7(b) shows a high resolution TEM image providing evidence of a phase separation between a pure Si nanocrystal (circled in red) and a Ce-rich cluster located in its vicinity (circled in blue). The latter is not sufficiently well-oriented to clearly evidence crystal planes on the micrograph. Nevertheless both STEM HAADF and STEM BF have shown that the Ce-rich clusters are crystalline. However, the main grains appear twinned or polycrystalline; this makes a structural determination difficult starting from HRSTEM micrographs. For the few monocrystalline grains that were observed, the coexistence of both crystalline $\mathrm{Ce}_{4.667}\left(\mathrm{SiO}_{4}\right)_{3} \mathrm{O}$ and $\mathrm{Ce}_{2} \mathrm{Si}_{2} \mathrm{O}_{7}$ compounds cannot be excluded in agreement with the $\mathrm{Ce}-\mathrm{Si}-\mathrm{O}$ phase diagram. ${ }^{21}$

To further confirm the formation of cerium silicate, we investigate the Ce-doped $\mathrm{SiO}_{1.5}$ film annealed at $1200{ }^{\circ} \mathrm{C}$ by FTIR spectroscopy. Fig. 8 displays the FTIR spectra of Ce-doped $\mathrm{SiO}_{1.5}$ films annealed at $1200{ }^{\circ} \mathrm{C}$ for different Ce concentrations ranging from $0.3 \%$ to $4 \%$. All spectra are dominated by welldefined lines at $800 \mathrm{~cm}^{-1}$ corresponding to the symmetric stretching mode of the $\mathrm{Si}-\mathrm{O}-\mathrm{Si}$ bond and at $1080 \mathrm{~cm}^{-1}$ corresponding to the asymmetric stretching mode of the $\mathrm{Si}-\mathrm{O}-\mathrm{Si}$ bond in $\mathrm{SiO}_{2}{ }^{22,23}$ Apart from these lines, we can further identify a rather broad band between $900 \mathrm{~cm}^{-1}$ and $975 \mathrm{~cm}^{-1}$ (see also the inset of Fig. 8). The intensity of this band increases as the Ce content in the films increases, thus suggesting that this feature is related to the presence of Ce. In the literature, ${ }^{24,25}$ several closely spaced peaks have been identified in the range $826-975 \mathrm{~cm}^{-1}$, which may be due to the formation of the $\mathrm{Ce}_{2} \mathrm{Si}_{2} \mathrm{O}_{7}$ or $\mathrm{Ce}_{4.667}\left(\mathrm{SiO}_{4}\right)_{3} \mathrm{O}$ compounds. Our FTIR investigations thus confirm the formation of a cerium silicate for high annealing temperatures.

Finally, we will discuss the general evolution observed during annealing of Ce-doped $\mathrm{SiO}_{1.5}$ thin films. The atom probe tomography measurements performed on the as-grown films (a)

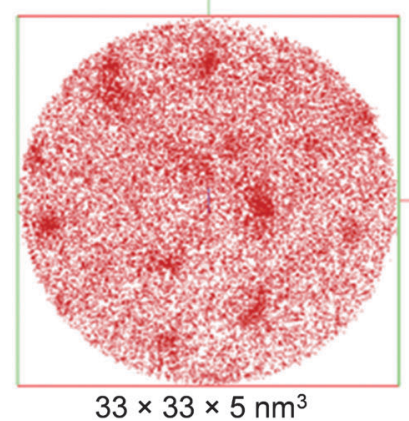

(b)

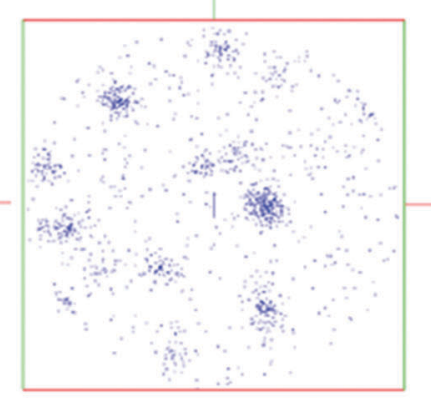

(c)

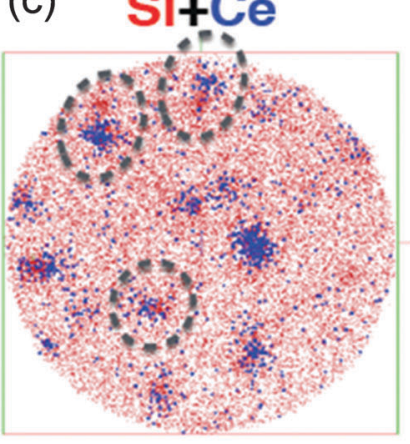

Fig. 6 Atom probe tomography analysis of the $3 \% \mathrm{Ce}$-doped $\mathrm{SiO}_{1.5}$ thin film annealed at $980{ }^{\circ} \mathrm{C}$. (a) Plane view of a $5 \mathrm{~nm}$ thick slice taken from the reconstructed volume. The Si atoms are shown as red dots, providing evidence of the presence of Si-rich clusters, (b) analogous plane view showing $\mathrm{Ce}$ atoms as blue dots, evidencing the presence of Ce-rich clusters, (c) superposition of the maps shown in (a) and (b) demonstrating that both $\mathrm{Si}$ - and Ce-rich clusters no longer have the same locations (also indicated by dashed circles). All the views have the size of $33 \times 33 \times 5 \mathrm{~nm}^{3}$. 


\section{$\mathrm{Si}+\mathrm{Ce}$}

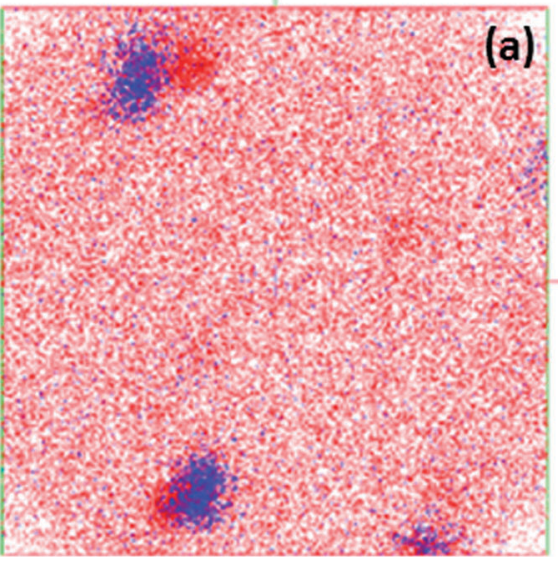

$33 \times 33 \times 5 \mathrm{~nm}^{3}$

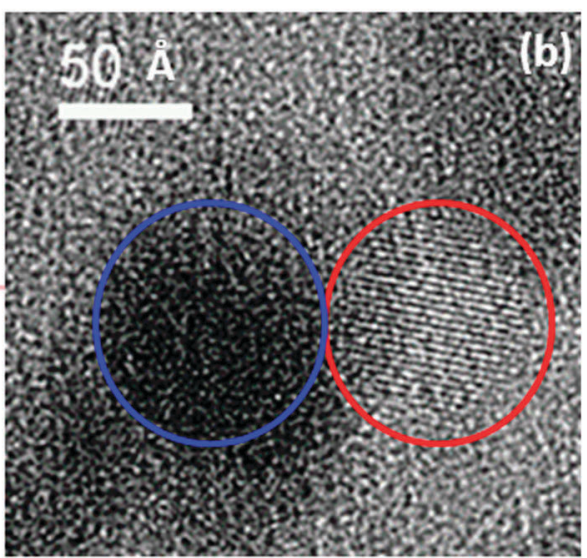

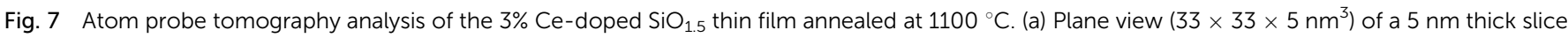

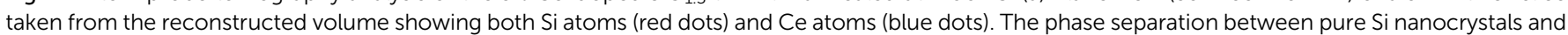

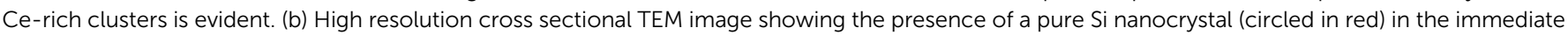
vicinity of a Ce-rich cluster (circled in blue).

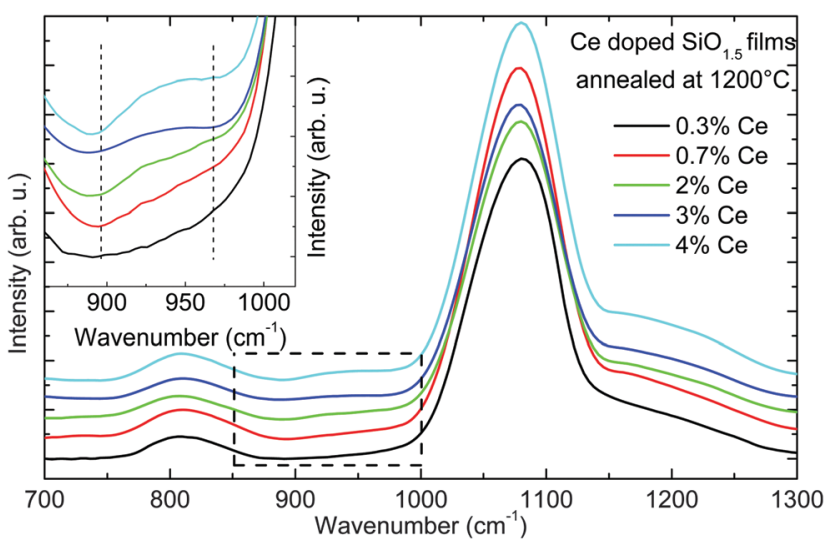

Fig. 8 FTIR spectra of $\mathrm{Ce}$-doped $\mathrm{SiO}_{1.5}$ thin films annealed at $1200{ }^{\circ} \mathrm{C}$ The Ce content is varied between $0.3 \%$ and $4 \%$. All spectra are vertically offset for clarity. The dashed area is enlarged in the inset. The vertical dashed lines in the inset indicate the wavenumber range in which features corresponding to the formation of a cerium silicate are expected.

show that Ce atoms are almost randomly distributed (not shown here). When the samples are annealed at $900{ }^{\circ} \mathrm{C}$, amorphous Ce-rich clusters have been identified by both STEM (Fig. 3) and APT measurements (Fig. 4). This indicates that Ce diffusion is thermally activated in our films. Moreover, as the annealing temperature increases up to $900{ }^{\circ} \mathrm{C}$, a demixtion occurs in the $\mathrm{SiO}_{1.5}$ films leading to $\mathrm{Si}$ atoms in excess in a matrix with a composition reaching $\mathrm{SiO}_{2}$. Both $\mathrm{Ce}$ and $\mathrm{Si}$ atoms will then diffuse and eventually accumulate at the pores/vacancies of the films, thus leading to Ce- and Si-rich clusters as shown in Fig. 4(c). At least up to the annealing temperature of $900{ }^{\circ} \mathrm{C}$, the evolution appears to be essentially governed by kinetics, i.e. by diffusion and clustering of both $\mathrm{Si}$ and Ce. When the films are further annealed at higher temperatures, thermodynamics takes over and the $\mathrm{Si}-\mathrm{O}-\mathrm{Ce}$ system moves towards stable compounds.
The formation of cerium silicates is, however, precluded at $900{ }^{\circ} \mathrm{C}$ since the thermal budget is still too low. ${ }^{21}$ According to the Ce-Si phase diagram, ${ }^{26}$ the formation of cerium silicides also appears to be unlikely for the Ce contents and annealing temperatures considered in our study. Moreover, we can also rule out the formation of $\mathrm{CeO}_{2}$ since we do not observe the wellknown Raman peak at $462 \mathrm{~cm}^{-1}$ in Fig. 5. This conclusion is further supported by the X-ray photoelectron spectroscopy data which do not show a significant increase of the $\mathrm{Ce}^{4+}$ related peak intensities as the annealing temperature increases. For annealing temperatures above $980{ }^{\circ} \mathrm{C}$, the formation of cerium silicates such as $\mathrm{Ce}_{2} \mathrm{Si}_{2} \mathrm{O}_{7}$ or $\mathrm{Ce}_{4.667}\left(\mathrm{SiO}_{4}\right)_{3} \mathrm{O}$ starts. At this temperature, the compositional analysis based on APT measurements has shown that the Si content in the clusters is about $24 \%$, which is much larger than the amount of $\mathrm{Si}$ required to form the cerium silicates (i.e. $18.2 \%$ for $\mathrm{Ce}_{2} \mathrm{Si}_{2} \mathrm{O}_{7}$ and $14.5 \%$ for $\left.\mathrm{Ce}_{4.667}\left(\mathrm{SiO}_{4}\right)_{3} \mathrm{O}\right)$. Consequently, the $\mathrm{Si}$ atoms in excess will be ejected and will agglomerate to form pure $\mathrm{Si}$ nanocrystals in the immediate vicinity of the cerium silicate clusters. We thus expect that thermodynamics is the main driving force leading to the formation of stable phases which in our case are $\mathrm{Si}, \mathrm{SiO}_{2}$ and $\mathrm{Ce}_{2} \mathrm{Si}_{2} \mathrm{O}_{7}$ or $\mathrm{Ce}_{4.667}\left(\mathrm{SiO}_{4}\right)_{3} \mathrm{O}$.

\section{Conclusions}

To summarize, we have investigated both the structural and optical properties of Ce-doped $\mathrm{SiO}_{1.5}$ thin films. The complex evolution of the Ce-related luminescence with the annealing temperature is well explained thanks to a complementarity of different nanoscale structural characterizations and vibrational spectroscopies. In particular, the strong PL decrease at $900{ }^{\circ} \mathrm{C}$ is related to the presence of Ce-rich clusters. At higher annealing temperatures, we were able to identify and characterize a phase separation occurring at a length scale below $10 \mathrm{~nm}$ between 
pure $\mathrm{Si}$ nanocrystals and Ce-rich clusters having a stoichiometry close to $\mathrm{Ce}_{2} \mathrm{Si}_{2} \mathrm{O}_{7}$ or $\mathrm{Ce}_{4.667}\left(\mathrm{SiO}_{4}\right)_{3} \mathrm{O}$. This is the first direct observation of a nanoscale phase separation in a solid state matrix. The cerium silicates are known to be luminescent, thereby explaining the increased Ce-related luminescence at $1100{ }^{\circ} \mathrm{C}$. At the present stage of our investigations, the microscopic driving force at the origin of the observed phase separation is not yet clearly identified. Further theoretical work using kinetic Monte Carlo simulations and/or even molecular dynamics or nano-thermodynamic simulations would be needed to clarify this important issue. This work brings a comprehensive view of the optical properties of Ce-doped Si-based layers in relation to their structure and then represents an important step towards the realization of blue light emitting devices fully compatible with the well-known Si technology.

\section{Notes and references}

1 S. Takeoka, M. Fujii and S. Hayashi, Phys. Status Solidi B, 2001, 224, 229-232.

2 G. Scardera, T. Puzzer, I. Perez-Wurfl and G. Conibeer, J. Cryst. Growth, 2008, 310, 3680-3684.

3 M. Zacharias, J. Heitmann, R. Scholz, U. Kahler, M. Schmidt and J. Blasing, Appl. Phys. Lett., 2002, 80, 661-663.

4 O. Jambois, H. Rinnert, X. Devaux and M. Vergnat, J. Appl. Phys., 2005, 98, 046105.

5 M. Fujii, M. Yoshida, Y. Kanzawa, S. Hayashi and K. Yamamoto, Appl. Phys. Lett., 1997, 71, 1198-1200.

6 E. Steveler, H. Rinnert and M. Vergnat, J. Appl. Phys., 2011, 110, 113518.

7 C. H. Liang, J. Cardin, C. Labbe and F. Gourbilleau, J. Appl. Phys., 2013, 114, 033103.

8 A. H. Morshed, M. E. Moussa, S. M. Bedair, R. Leonard, S. X. Liu and N. El-Masry, Appl. Phys. Lett., 1997, 70, 1647-1649.
9 W. C. Choi, H. N. Lee, E. K. Kim, Y. Kim, C. Y. Park, H. S. Kim and J. Y. Lee, Appl. Phys. Lett., 1999, 75, 2389-2391.

10 L. Kepinski, D. Hreniak and W. Strek, J. Alloys Compd., 2002, 341, 203-207.

11 J. Li, O. Zalloum, T. Roschuk, C. Heng, J. Wojcik and P. Mascher, Appl. Phys. Lett., 2009, 94, 011112.

12 J. Weimmerskirch-Aubatin, M. Stoffel, X. Devaux, A. Bouché, M. Vergnat and H. Rinnert, Phys. Status Solidi C, 2014, 11, 1630-1633.

13 J. Weimmerskirch-Aubatin, M. Stoffel, A. Bouché, P. Boulet, M. Vergnat and H. Rinnert, J. Alloys Compd., 2015, 622, 358-361.

14 K. Thompson, D. Lawrence, D. Larson, J. Olson, T. Kelly and B. Gorman, Ultramicroscopy, 2007, 107, 131-139.

15 E. Talbot, R. Lardé, F. Gourbilleau, C. Dufour and P. Pareige, Europhys. Lett., 2009, 87, 26004.

16 A. Pfau and K. D. Schierbaum, Surf. Sci., 1994, 321, 71-80.

17 E. J. Preisler, O. J. Marsh, R. A. Beach and T. C. McGill, J. Vac. Sci. Technol., B: Microelectron. Nanometer Struct. - Process., Meas., Phenom., 2001, 19, 1611-1618.

18 M. Seah, Surf. Sci., 1999, 420, 285-294.

19 M. Seah, I. Gilmore and S. Spencer, Surf. Sci., 2000, 461, 1-15.

20 H. Rinnert, M. Vergnat and A. Burneau, J. Appl. Phys., 2001, 89, 237-243.

21 A. Cuneyt Tas and M. Akinc, J. Am. Ceram. Soc., 1994, 77, 2953-2960.

22 S. Y. Lin, J. Appl. Phys., 1997, 82, 5976-5982.

23 H. Z. Song, X. M. Bao, N. S. Li and X. L. Wu, Appl. Phys. Lett., 1998, 72, 356-358.

24 L. Kepinski, M. Wolcyrz and M. Marchewka, J. Solid State Chem., 2002, 168, 110-118.

25 I. F. Andreev, A. N. Sokolov, A. M. Shebyakov, Y. P. Tarlakov and N. A. Toropov, J. Appl. Spectrosc., 1971, 14, 263-265.

26 M. V. Bulanova, P. N. Zheltov, K. A. Meleshevich, P. A. Saltykov and G. Effenberg, J. Alloys Compd., 2002, 345, 110-115. 